\title{
DRAINAGE AND RETENTION ENHANCEMENT OF A WHEAT STRAW-CONTAINING PULP FURNISH USING MICROPARTICLE RETENTION AIDS
}

\author{
Alexey Vishtal, ${ }^{\mathrm{a}, *}$ Päivi Rousu, ${ }^{\mathrm{a}}$ Tom Hultholm, ${ }^{\mathrm{b}}$ Kati Turku, ${ }^{\mathrm{a}}$ Petteri Paananen, ${ }^{\mathrm{a}}$ \\ and Jari Käyhkö ${ }^{a}$
}

\begin{abstract}
The usage of non-wood pulps in furnishes for the production of various paper grades is a real alternative for the substitution of wood pulp in papermaking. In terms of the papermaking process, the main limiting factor for non-wood pulp utilization is poor dewatering. This problem can be partially solved by means of retention aids, and the modern microparticle-based retention aids are very promising for this application. In this study the main aim was to characterize how the microparticle retention systems affect the retention, dewatering, and formation of a non-wood pulp furnish and how these effects and mechanisms differ when compared to normal wood pulp. The performance of several commercially available retention aids was studied by making dynamic sheet forming tests for reference and an organosolv wheat straw furnish. The emphasis in the experiments was on drainage enhancement. The maximum drainage gain obtained with the bentonite-CPAM retention aid system was about $5 \%$. Despite the improved drainage, dewatering of the reference furnish was better than for the non-wood containing furnish.
\end{abstract}

Keywords: Wheat straw pulp; Retention; Drainage; Microparticle retention aids; Formation; Organosolv; Bentonite-CPAM

Contact Information: a) Lappeenranta University of Technology, Chemical Technology Department, Laboratory of Pulp and Paper technology; b) UPM-Kymmene Oy, UPM Research Centre Lappeenranta Finland; *Corresponding author: alexey.vishtal@lut.fi

\section{INTRODUCTION}

The usage of the non-wood pulps in furnishes for various paper grades has been attracting increased interest, especially in Asia. For instance, paper consumption and production are increasing the fastest in China; there is a serious shortage of wood raw material, but non-wood material is abundantly available. However, there are several problems associated with the utilization of non-wood pulps. In addition to the main problem relating to the environmental discharges of conventional soda/soda-AQprocesses, the poor dewatering properties of typical non-wood pulps are challenging. The environmental problems and partially the dewatering problems can be solved by selecting a suitable pulping process (Nie 2007; Rousu et al. 2010). Dewatering can also be improved by a partial removal of fines (Cheng 1994; Cheng and Paulapuro 1996a and b; Rousu and Hytönen 2007).

However, there is a lack of knowledge as to what extent dewatering can be improved using retention aids. The influence of retention aids on the retention and drainage of non-wood pulps has mainly concentrated on the utilization of single- 
component retention aids (Ye et al. 1990; Yang et al. 1996; Zhu et al. 1997; Liu et al. 2000; Hu et al. 2000; Xuan and Huiren 2000). The use of a single-component retention aid is not compatible with modern paper machines where the drainage, retention, and formation parameters should be fully controlled. Microparticle retention aids provide good drainage and retention levels with good formation when applied in wood pulp furnishes. The utilization of microparticle retention aids is a potential way to improve the processability of non-wood pulps. The influence of the microparticle retention aids on the dewatering of non-wood pulps has been previously evaluated only in the article by Wågberg et al. (1990).

The performance of different microparticle retention aid systems was studied in this work by making experiments with reference and non-wood containing furnish. The non-wood furnish contained 50 \% (by mass) of organosolv wheat straw pulp. Organosolv wheat straw pulp was produced by Formicofib ${ }^{\mathrm{TM}}$ technology. This technology utilizes the TCF bleaching sequence, and has a significantly lower water consumption and COD load compared to conventional mills, which allows some environmental problems to be overcome (Rousu et al. 2002; Nie 2007). Also this process has superior energy efficiency (Worrel et al. 2008). In comparison with the conventional Soda-AQ and sulfate wheat straw pulps, the organosolv wheat straw pulp used in this study has different papermaking properties. The main advantage of this pulp is improved dewatering; the drainage of never-dried organosolv pulp can be compared with the drainage of once-dried soda-AQ pulp. However, it is still an issue to be improved. It also shows a higher dry solids level after wet pressing and a higher wet tensile strength measured at the same dry solids content (Rousu et al. 2010; Muravyev 2010). The main aim of this study was to obtain information about the influence of microparticle retention aids on the drainage and retention of non-wood containing furnish. Moreover, special attention was paid to the dewatering of non-wood pulp containing furnish.

\section{EXPERIMENTAL}

\section{Pulps, Furnishes and Retention Chemicals}

The never-dried bleached wheat straw pulp was supplied by Chempolis Oy (Oulu, Finland). This organosolv pulp was prepared using Formicofib ${ }^{\mathrm{TM}}$ technology, which is based on biosolvent containing formic acid (Rousu et al. 2002). The eucalyptus and pine pulps were conventional once-dried kraft market pulps. The wood pulps were refined in a Voith-Sulzer refiner. The wheat straw pulp was disintegrated in a British disintegrator according to ISO 5263-1. The ${ }^{\circ} \mathrm{SR}$ measurements were carried out according to a standard procedure (SCAN-C 19:65). Fiber dimensions and fines content were measured using an L\&W FiberTester. The essential features of pulps used in the experiment are shown in Table 1.

Two different furnishes were utilized in this study: non-wood and reference. The non-wood furnish contained a mixture of different wood pulps and wheat straw pulp, while the reference furnish only consisted of wood pulps. The furnishes also contained filler and wet-end starch. The composition of the experimental furnishes can be found in Table 2. 
Table 1. Properties of the Pulps Utilized in the Experiment

\begin{tabular}{|l|c|c|c|}
\hline Parameter & Wheat straw pulp & Eucalyptus pulp & Pine pulp \\
\hline Fiber length*; mm & 0.672 & 0.728 & 2.050 \\
\hline Fiber width; $\mu \mathrm{m}$ & 16.0 & 15.1 & 29.8 \\
\hline Fines; \% & 42.0 & 5.2 & 4.8 \\
\hline SR number; ${ }^{*}$ & $24^{\star *}$ & 32 & 27 \\
\hline Ash content; \% & 7.65 & 0.14 & 0.24 \\
\hline Origin of the process & formicofib $^{\text {TM }}$ & Kraft & Kraft \\
\hline Applied drying & No & Yes & Yes \\
\hline Zeta potential; $\mathrm{mV}$ & -31.2 & -73.6 & -58.9 \\
\hline
\end{tabular}

*Length weighted fiber length, ${ }^{* *}$ Not refined

Table 2. Composition of the Furnishes used in the Experiment

\begin{tabular}{|l|c|c|}
\hline Component & Non-wood furnish & Reference furnish \\
\hline Pine pulp; \% & 15 & 15 \\
\hline Eucalyptus pulp; \% & 35 & 85 \\
\hline Wheat straw pulp; \% & 50 & 0 \\
\hline Filler*; \% & 25 & 25 \\
\hline Wet-end starch**; kg/t of pulp & 2 & 2 \\
\hline
\end{tabular}

* Fincarb 6002 (GCC) on fibers;** Raisamyl 115 (0.2\% on fibers) only in bentoniteCPAM and silica-CPAM retention aids

The following retention chemicals were utilized in this study: three types of cationic polyacrylamides, two kinds of microparticles (bentonite and silica sol), and cationic starch. Some general information about the retention chemicals used in the experiment is shown in Table 3.

Table 3. Characterization of the Retention Chemicals used in the Experiments

\begin{tabular}{|l|c|c|c|c|}
\hline Chemical & Origin & Structure & $\mathbf{M W}^{*}$ & CD $^{* *}$ \\
\hline K 1390 & Kemira & Cationic Polyacrylamide & $2^{*} 10^{7} \mathrm{~g} / \mathrm{mol}$ & $1.1 \mathrm{meq} / \mathrm{g}$ \\
\hline K 280 & Kemira & Cationic Polyacrylamide & $5^{\star} 10^{6} \mathrm{~g} / \mathrm{mol}$ & $2.1 \mathrm{meq} / \mathrm{g}$ \\
\hline K 211 & Kemira & Cationic Polyacrylamide & $5.8^{\star} 10^{6} \mathrm{~g} / \mathrm{mol}$ & $0.15 \mathrm{meq} / \mathrm{g}$ \\
\hline Bentonite & Allied Colloids & Na montmorillonite & - & - \\
\hline Silica NP 442 & Eka & Anionic silica sol & - & - \\
\hline Raisamyl 115 & Raisio (Ciba) & Cationic Starch (Potato) & - & $0.05 \mathrm{meq} / \mathrm{g}$ \\
\hline
\end{tabular}

* MW- Molecular weight; CD**- Charge Density

\section{Drainage and Retention Test Procedure}

The evaluation of the retention and drainage was conducted using Turbulent Pulse Sheet Former equipment (TPSF). This device employs controlled vacuum pulsations during the drainage of the sheet (Hubbe 2003). The drainage variable measured in the experiments was the time needed to dewater $1000 \mathrm{~mL}$ of the pulp suspension containing $1.6 \mathrm{~g}$ of dry matter $(1.2 \mathrm{~g}$ of fibers $+0.4 \mathrm{~g}$ of filler) under vacuum pulsations in TPSF. The disappearance of the water mirror from above the fiber cake formed was taken as the end point of the measurement. The drainage time was measured with a timer. The total 
and filler retention were measured by standard procedure (TAPPI T211 om-93). The TPSF adjustments were as follows:

- air pressure $35 \mathrm{kPa}$

- vacuum pulsation frequency 40

- $\quad$ stirring speed 750 rpm (counter-clockwise direction)

There were several features in the testing of each retention aid. For the bentoniteCPAM (Cationic Polyacrylamide) and silica-CPAM retention aids, cationic polyacrylamides were added into the furnish containing fibers and fillers at a stirring speed of 750 rpm and retained for 10 seconds. Then bentonite/silica was added and retained for 10 seconds. After that, the vacuum pump was switched on and the drainage time counting was started.

For the silica-starch retention aid, the furnish sample was diluted to $900 \mathrm{~mL}$ and then put into the TPSF apparatus vessel. The starch was diluted to $50 \mathrm{~mL}$ and added to the fiber slurry in the TPSF. The fiber and starch was mixed for 30 seconds and then 50 $\mathrm{mL}$ of filler suspension was added to the stock. Silica was added after 5 seconds. The mixture was retained for 10 seconds. In case of silica-starch retention aid there was no wet-end starch added. For the each dosage, 5 parallel tests were performed, and an average value was taken as the result.

\section{RESULTS AND DISCUSSION}

\section{Influence of the Polyacrylamide-bentonite Retention Aid on the Drainage and Retention of Non-wood Pulp}

The bentonite-CPAM retention aid showed the best performance among the retention aids tested and is therefore described in detail. Figure 1 shows the influence of the CPAM dosage on the drainage time, while the bentonite dosage was kept constant at a level of $5 \mathrm{~kg} / \mathrm{t}$. Three distinct PAMs were used in order to observe the influence of charge density and molecular weight on the performance of the retention system.
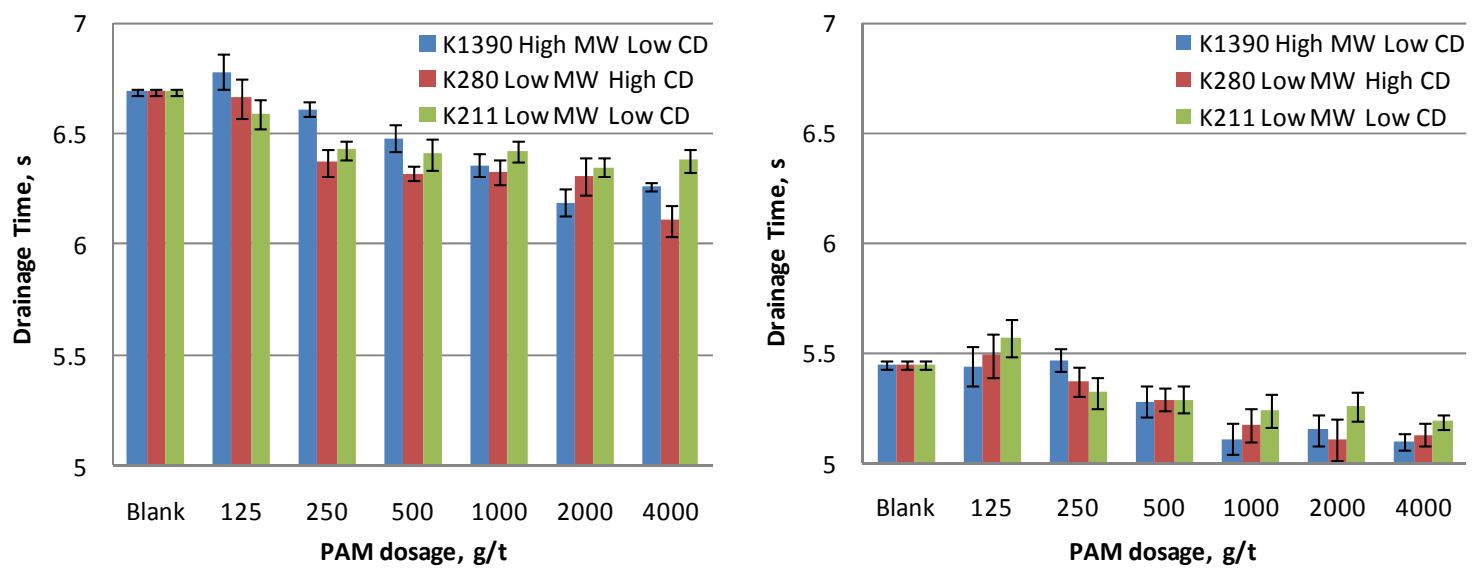

Fig. 1. Drainage time of the non-wood (left) and reference (right) furnishes versus CPAM dosage in the bentonite-CPAM system 
As can be seen from Fig. 1, the addition of polyacrylamides had a positive influence on the drainability of non-wood furnish, and the improving effect was slightly stronger compared to the reference pulp. The maximum drainage gain was about 0.5 seconds and was obtained with a low molecular weight CPAM with a high charge density (K 280) at a dosage of $4000 \mathrm{~g} / \mathrm{t}$. However, such high dosages have a negative influence on the formation. In practice, the dosage levels are normally clearly below $1000 \mathrm{~g} / \mathrm{t}$. The average decrease in the drainage time at a recommended dosage of $500 \mathrm{~g} / \mathrm{t}$ can be stated as 0.25 seconds and 0.15 seconds for non-wood and reference furnishes, respectively. The best result was obtained with CPAM K 280. Even though the absolute decrease in drainage time does not seem significant, in the conditions of a real paper machine, such a change could bring significant benefits, e.g. to the running speed. In these experiments addition of retention chemical also increased sheet basis weight through improved retention, which then also has increasing effect on the observed drainage time. It could be speculated that the decrease in drainage time in a real paper machine would be higher. With the non-wood furnish, the dewatering time was clearly higher compared to the reference pulp. Cheng and Paulapuro (1996a) have reported that the large Specific Surface Area (SSA) is the most evident cause for the poor drainability of wheat straw pulp. The key role of the large SSA is in increasing the contacts between the fluid and internal surface of the fibers, leading to an increase in drainage resistance. This model cannot be applied as a pattern. Besides SSA, there are also other shape factors that affect drainage (Liimatainen 2009).

The flocculation of the furnish components is the core of drainage and retention improvement with the bentonite-CPAM retention aid. It was shown by Antunes et al. (2008a and b) that any flocculation is favorable for dewatering. Liimatainen et al. (2009) have investigated the effect of CPAM addition on filtering resistance of eucalyptus and pine pulp, and shown that the maximum filtering speed gain occurred at a CPAM dosage of about $2.5 \mathrm{~kg}$ per tonne of pulp. The main occurrence that can explain such phenomena is the decrease in surface area of the fibers due to intensive flocculation. This is especially true in the case of non-wood fines because they have a sufficiently larger surface area in comparison with wood pulps (Guo et al. 2009). It may be suggested that non-wood pulp fines have attached to the surface of the fibers, thus decreasing total surface area of the sheet.

Polymer molecular weight and charge density are also important factors for dewatering. As can be seen from Fig. 1, improvements in drainage as a result of addition of polymers K 1390 and K280 were clearly higher than in the case of polymer K 211. In the case of K 1390, this can be explained by the high molecular weight and in the case of K 280 by the high charge density. K 211 forms smaller and weaker flocs, which finally yield poor performance in comparison with these other polymers.

The influence of the bentonite-CPAM retention aid on the filler retention of nonwood and reference furnishes is shown in Fig. 2. The figure shows that the bentoniteCPAM retention aid provided a sufficient increase in the filler retention. According to the curves in Fig. 2, it is possible to say that retention increased up to a dosage of $1000 \mathrm{~g} / \mathrm{t}$ of CPAM on the pulp, and thereafter the increase in filler retention was less significant. 

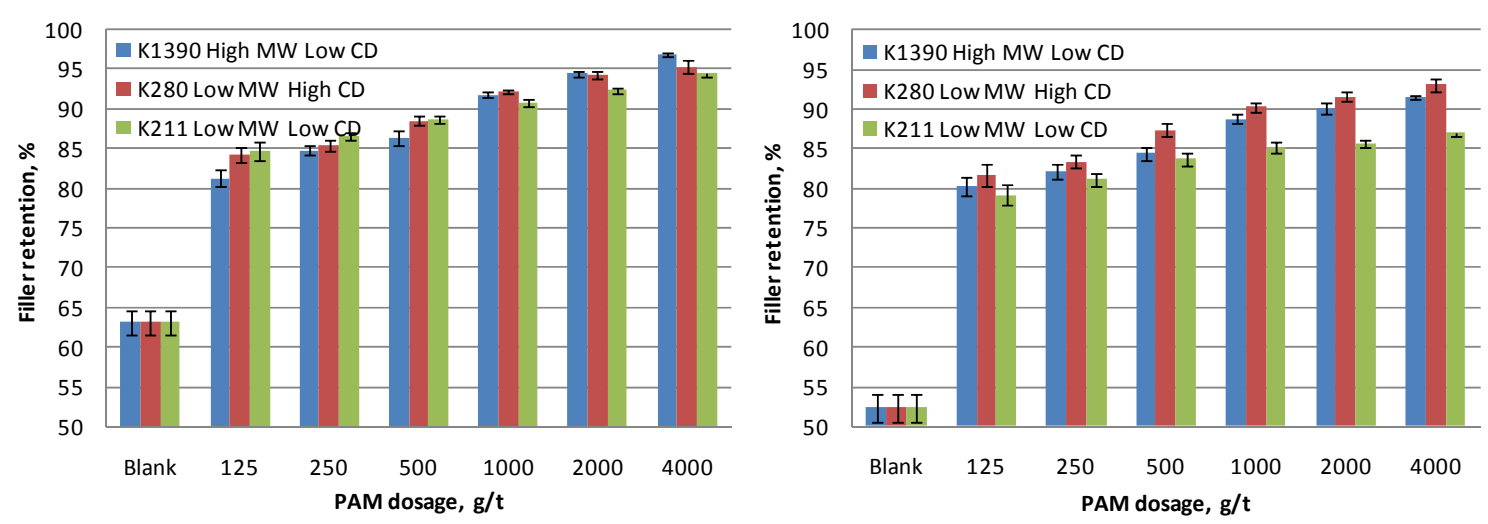

Fig. 2. Filler retention of non-wood (left) and reference (right) furnishes versus PAM dosage in the bentonite-PAM system.

The effects in Fig. 2 can be explained in such way that the binding strength and entrapping ability of the flocs formed by the synergistic action of CPAM and bentonite reach their maximum at a dosage of $1000 \mathrm{~g} / \mathrm{t}$ of CPAM on the pulp. This statement originates from the work of Cho et al. (2006). Basically, total and filler retention follow the same tendency, and the retention increases with polymer dosage. Polymer addition has brought a significant increase in filler retention (more than 20\%). Polymer K 211 was effective at low dosages in non-wood furnishes, but in other cases it was not as effective as the other polymers. We could assume that this is related to the conformation of polymer on the surface. For example, the low CD polymer is extending more outwards from the surface, and that's why the low CD and low MW polymer works quite well with low dosages. With higher dosages, this mechanism no longer helps, and a high MW or high CD polymer gives better retention.

According to Fig. 2, the filler retention of the reference furnish was lower than for the non-wood containing furnish. This fact can be explained by the higher amount of fines in non-wood furnish. It could be highlighted that the gain in filler retention caused by the retention aid addition was higher for the reference furnish. This could be due to the more porous sheet structure obtained with the reference furnish; individual filler particles can easily escape through the pores, but filler aggregates formed by the retention aids are retained better. The total retention of the reference furnish was almost the same as with the non-wood furnish due to the higher retention of more coarse fiber material.

The nature of the non-wood fibers can play its own significant role in filler retention. It has been shown by Solberg and Wågberg (2000) that filler retention depends on the amount and size of the pores in the fiber cake formed. The high flexibility of nonwood fibers and big amounts of fine material can decrease the amount and the size of the pores, thus improving filler retention. However, it seems that this occurrence has a detrimental influence on the drainage time.

Figure 3 shows the effect of the bentonite-CPAM retention aid on the fines retention for non-wood-containing and reference furnishes. 


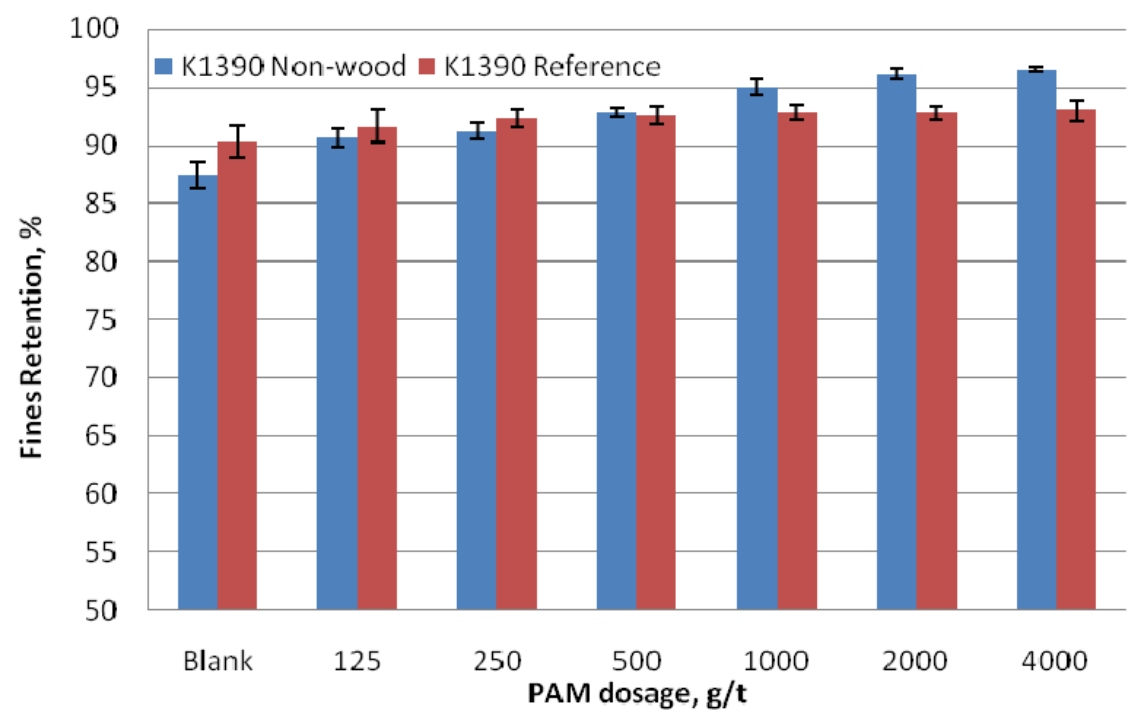

Fig. 3. CPAM (K1390 High MW Low CD) dosage versus fines retention of non-wood and reference furnish

Figure 3 allows us to make several suggestions regarding the influence of CPAM dosage on fines retention. In the blank tests, the fines retention of the non-wood furnish was approx. 3\% percent lower than for the reference furnish. Correspondingly, with increasing CPAM dosages the fines retention becomes equal to the reference furnish and finally exceeds it. It is possible to suggest that in the blank test, the fines of the non-wood furnish can penetrate through the forming wire due to the low attraction forces between the furnish components. The synergistic action of the CPAM and bentonite significantly improves fines retention, especially in the case of a non-wood furnish. It is worth mentioning that non-wood and wood fines differ significantly from each other, in their shape and origin (Ilvessalo-Pfäffli, 1995). Also, the fines of non-wood pulp are primary fines, while the eucalyptus and pine pulp fines are mostly secondary and originate from the refining process. The retention of wood fines remained at approximately the same level without significant dependence on the CPAM dosage. This suggests that some of the fine material was not retained, neither by filtration through the fiber cake nor via the action of the retention aid. On the other hand, the different origins and structures of nonwood fines make their own contribution to retention behavior; it seems that the fines with this non-wood pulp had a good response to retention aid dosage.

\section{Influence of the Starch Dosage in Silica-Starch Retention Aid on the Zeta Potential of the Furnishes}

The retention aids based on the utilization of the silica microparticles dominate the market of retention chemicals. About 347 paper machines with a combined production of 26.3 million metric tons of paper utilize silica-based retention aids. The first retention aid utilizing silica microparticles was brought onto the market in 1980 (Otterstedt and Greenwood, 2006). The main advantages of this system are its simplicity of application and affordable price. 
Starch dosages and suitable starch types were verified by measuring the zeta potential before the experiments. According to Hubbe and Hietmann (2007) and Khosravani et al. (2010), the silica-starch retention aid can maximize its performance in drainage enhancement when the zeta potential lies in a range of -5 to +5 . Electrostatic interactions between the furnish components are minimized in this case, which is favorable for water removal. The results of the zeta potential study are shown in Fig. 4.

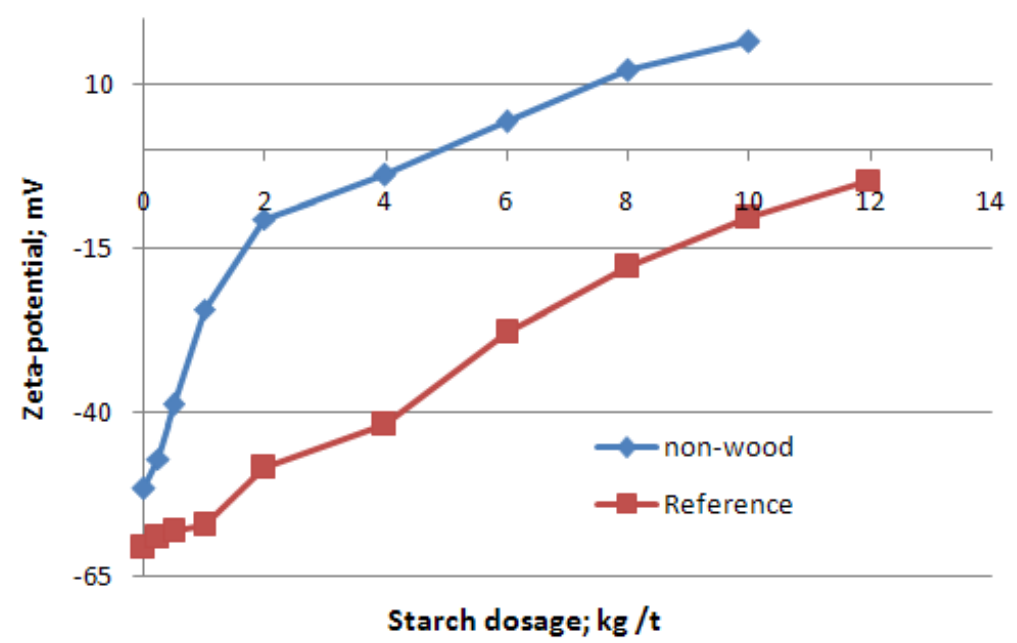

Fig. 4. Starch dosage vs. zeta potential for the reference and non-wood furnishes (kg/t of pulp)

As can been seen from Fig. 4, the non-wood furnish initially had a less negative zeta potential, and consequently the response to the starch dosage was far better than for the reference furnish. The zeta-potential reached a zero level at dosages of $0.4 \%$ and $1.2 \%$ for non-wood furnish and reference furnish, respectively. This fact also indicates a rather high anionicity for the reference furnish. The lower anionicity of the non-wood furnish can originate from the pulping process and the absence of refining in the case of wheat straw pulp. The low hemicelluloses content in the wheat straw pulp can also influence the zeta potential of the furnish. The retention aids dosages in the experiment were justified according to the zeta potential data; dosages were varied in the range of 0.4 to $1.6 \%$ starch on the fibers. The influence of the starch/silica dosage on the dewatering of the non-wood and reference furnishes is shown in Fig. 5.

As can be seen from Figs. 4 and 5, at the starch dosages where the zeta potential was about 0 , dewatering of the stock was the best. This suggestion can be applied both to the non-wood and reference furnishes. Such an occurrence confirms the fact that by keeping the zeta potential in a range of $-5-+5$, it is possible to enhance stock dewatering. A further increase in the starch dosage impedes drainage.

\section{SEM Investigation of the Paper Sheets}

The difference in the retention/drainage behavior of the reference and non-wood furnishes can be explained by the structural distinctions in the sheets. SEM micrographs from the surfaces of the sheets (500x) and z-direction were taken. The micrographs of the sheets without retention aids (blank) of the reference sheet are shown in Fig. 6 and those of the non-wood in Fig. 7. 


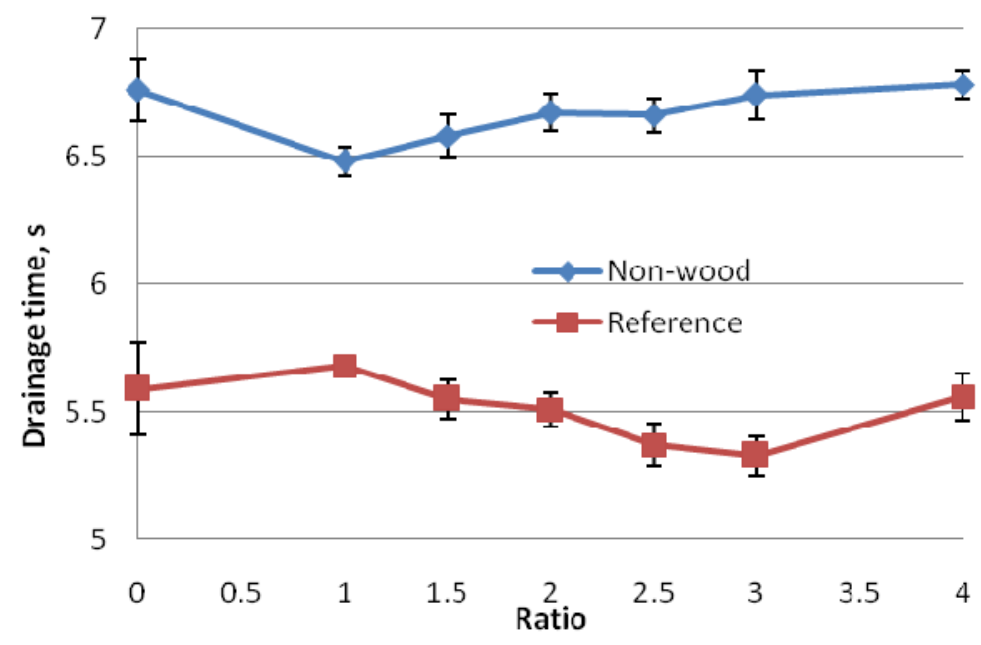

Fig. 5. Influence of the ratio of starch/silica dosage on the dewatering of the non-wood and reference furnishes. Silica dosage was at a constant level of $4 \mathrm{~kg} / \mathrm{t}$ on the fibers
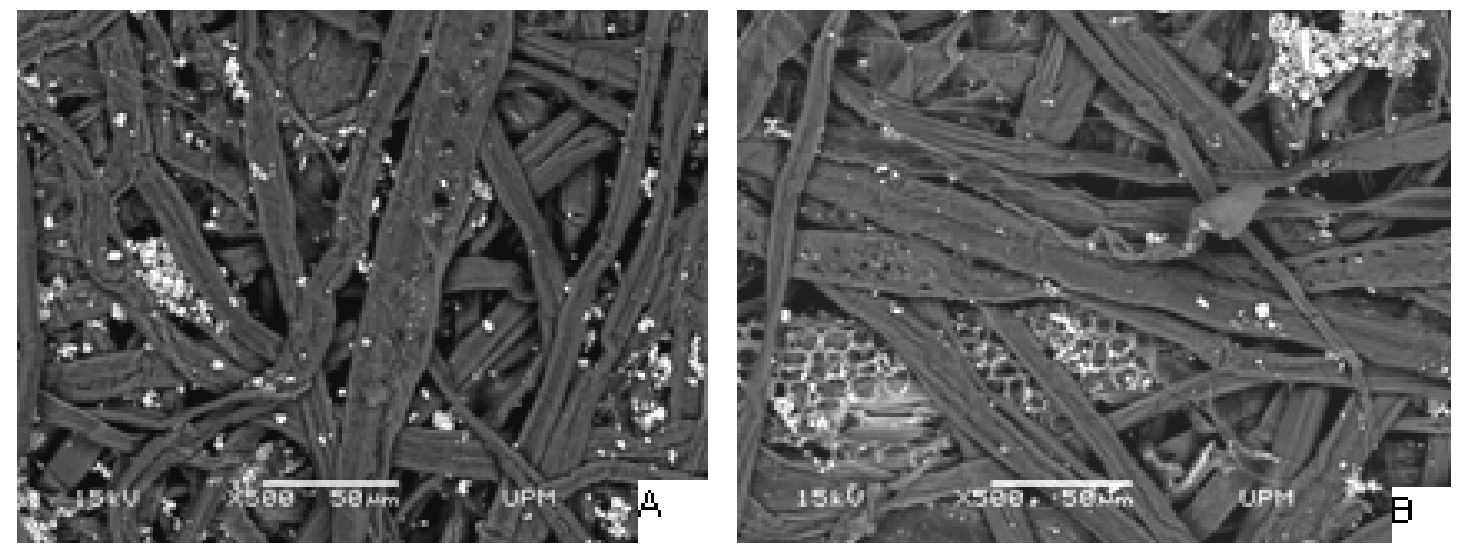

Fig. 6. SEM pictures of the reference (A) and non-wood (B) sheets (no retention chemicals, magnification 500x)

As can been seen from Figs. 6 and 7, the filler distribution in the z-direction with the reference sheet was not as even as with the non-wood sheet. It is possible to suggest that this is a consequence of the different resistance to fluid flow. The surface micrograph with the reference sheet clearly shows that there were quite big pores and cavities in the sheet, through which the filler particles could flow away. The relatively long and rigid fibers of wood pulp cannot form a uniform sheet with an even resistance to the fluid flow; thus the filler particles have been retained only in the places with high fiber density. It is logical to assume that non-wood sheet is denser and the fiber material is organized more tightly than in the reference sheet due to the higher amounts of fines.

Figures 8 and 9 show SEM pictures of the sheets of reference and non-wood furnishes with the retention aids added. The filler retention was $84.3 \%$ and $85.1 \%$ in the case of non-wood and reference furnish, respectively. 

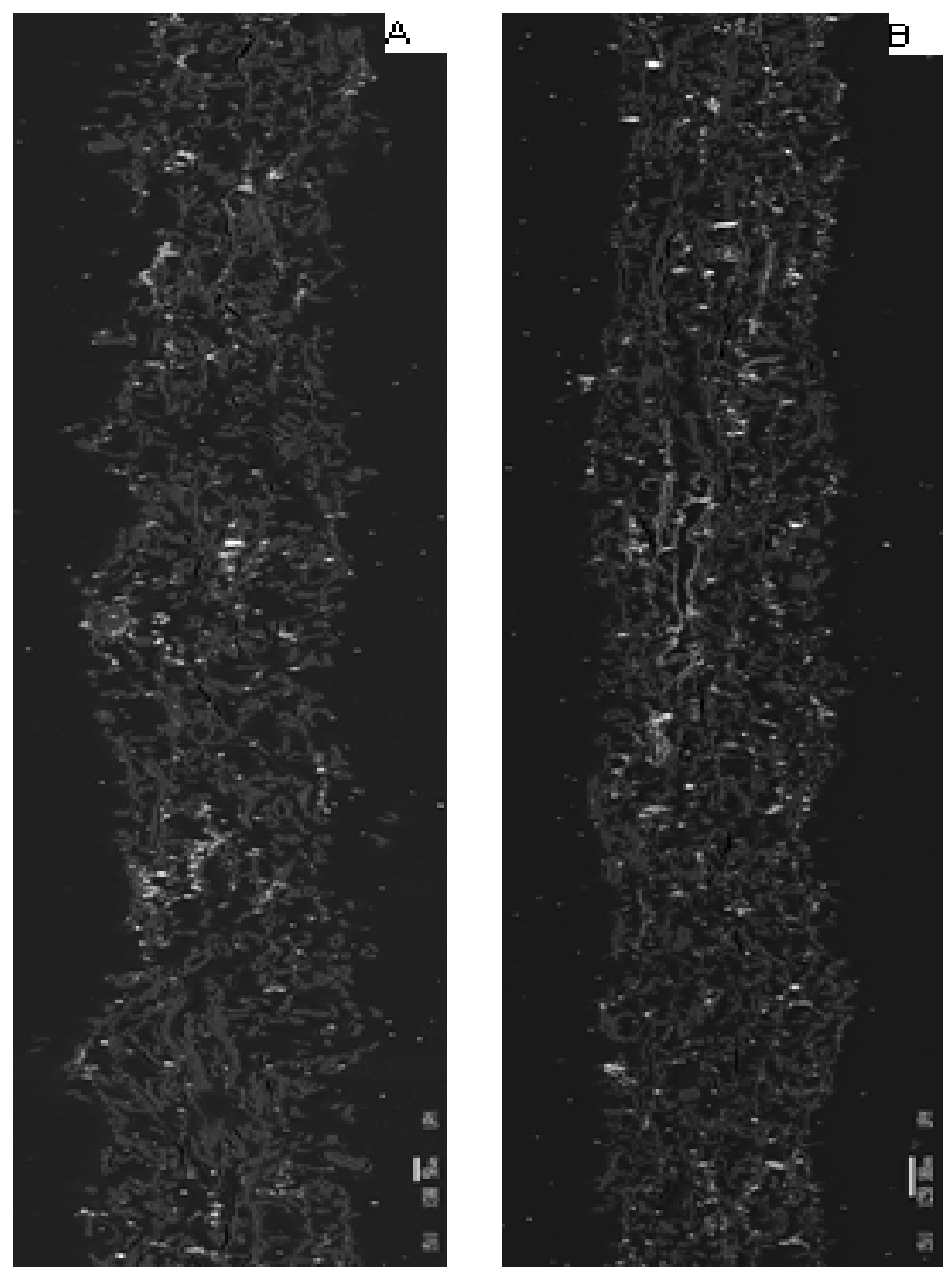

Fig. 7. Z-directional profiles of reference (A) and non-wood (B) sheets (magnification 500x)
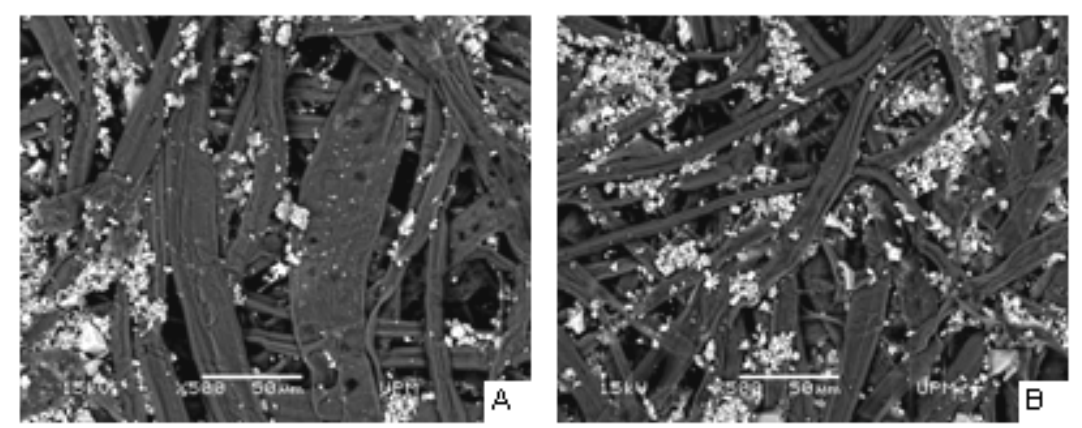

Fig. 8. SEM pictures of the reference sheet (A) (CPAM K211 dosage $1000 \mathrm{~g} / \mathrm{t}$, bentonite dosage $5 \mathrm{~kg} / \mathrm{t}$, filler retention level 85.1) and non-wood sheet (B) (CPAM K280 dosage $125 \mathrm{~g} / \mathrm{t}$, bentonite dosage $5 \mathrm{~kg} / \mathrm{t}$, filler retention level $84.3 \%$ ) 

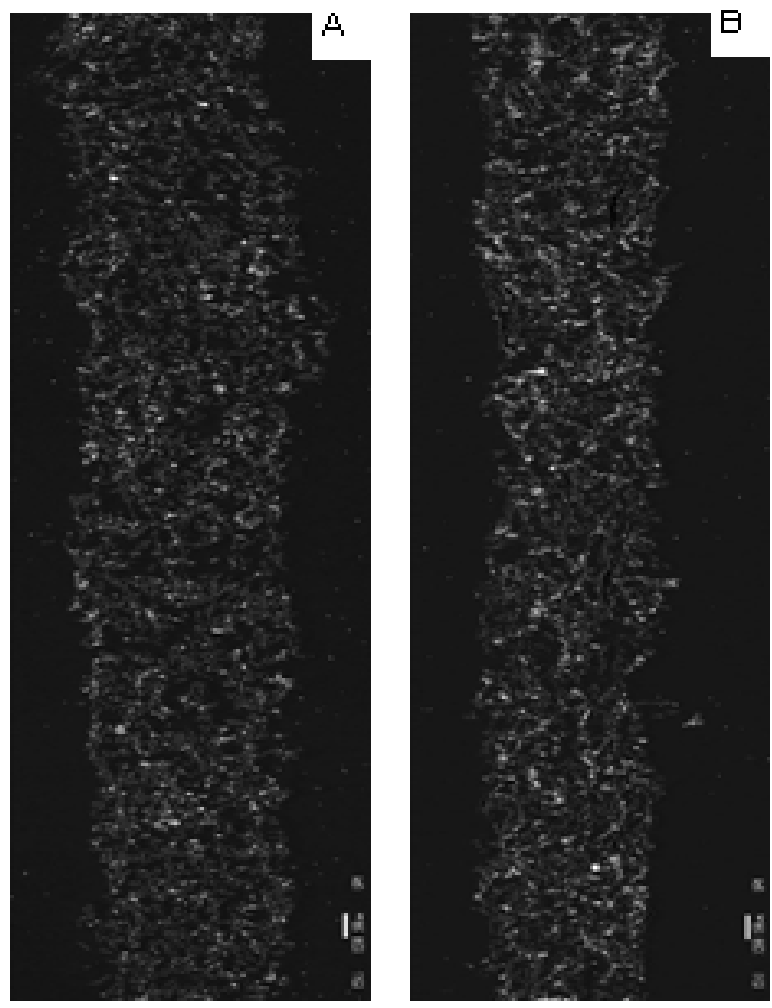

Fig. 9. Z-directional profile of the reference sheet (A) (CPAM K211 dosage 1000g/t, bentonite dosage $5 \mathrm{~kg} / \mathrm{t}$, filler retention level 85.1) and non-wood sheet (B) (CPAM K280 dosage 125g/t, bentonite dosage $5 \mathrm{~kg} / \mathrm{t}$, filler retention level $84.3 \%$ ) (magnification 500x)

As can been seen from Figs. 8 and 9, the addition of retention chemicals significantly improved the filler retention for the non-wood and reference furnishes. It can be seen that the filler in the sheets was distributed quite evenly and there was no major difference between the reference and non-wood furnish. However, the dosage level required for an equal retention level was about 8 times higher for the reference furnish.

\section{The Effect of Various Retention Aids on Formation}

The effect of various retention aids on formation is shown in Fig. 10 (see data also in Appendix 1). As can be seen from Fig. 10, each of the tested retention aids had a negative effect on the formation of the sheets. The silica/starch retention aid gave the best formation out of the all the retention aids.

The poor specific formation of the reference furnish in comparison with the nonwood furnish can be explained by the higher fiber length of wood fibers. It is well known that longer and straight fibers have a bigger affinity to crowding and as a consequence to flocculation (Kerekes and Schell 1995). Better formation of the non-wood sheet can also be caused by the fines in the wheat straw pulp, which have a large specific surface area (Cheng 1994). The large surface area in relation to the linear dimensions allows the fines to settle in the thin places of the fiber mat, thus improving formation (Vainio and Paulapuro 2007). 


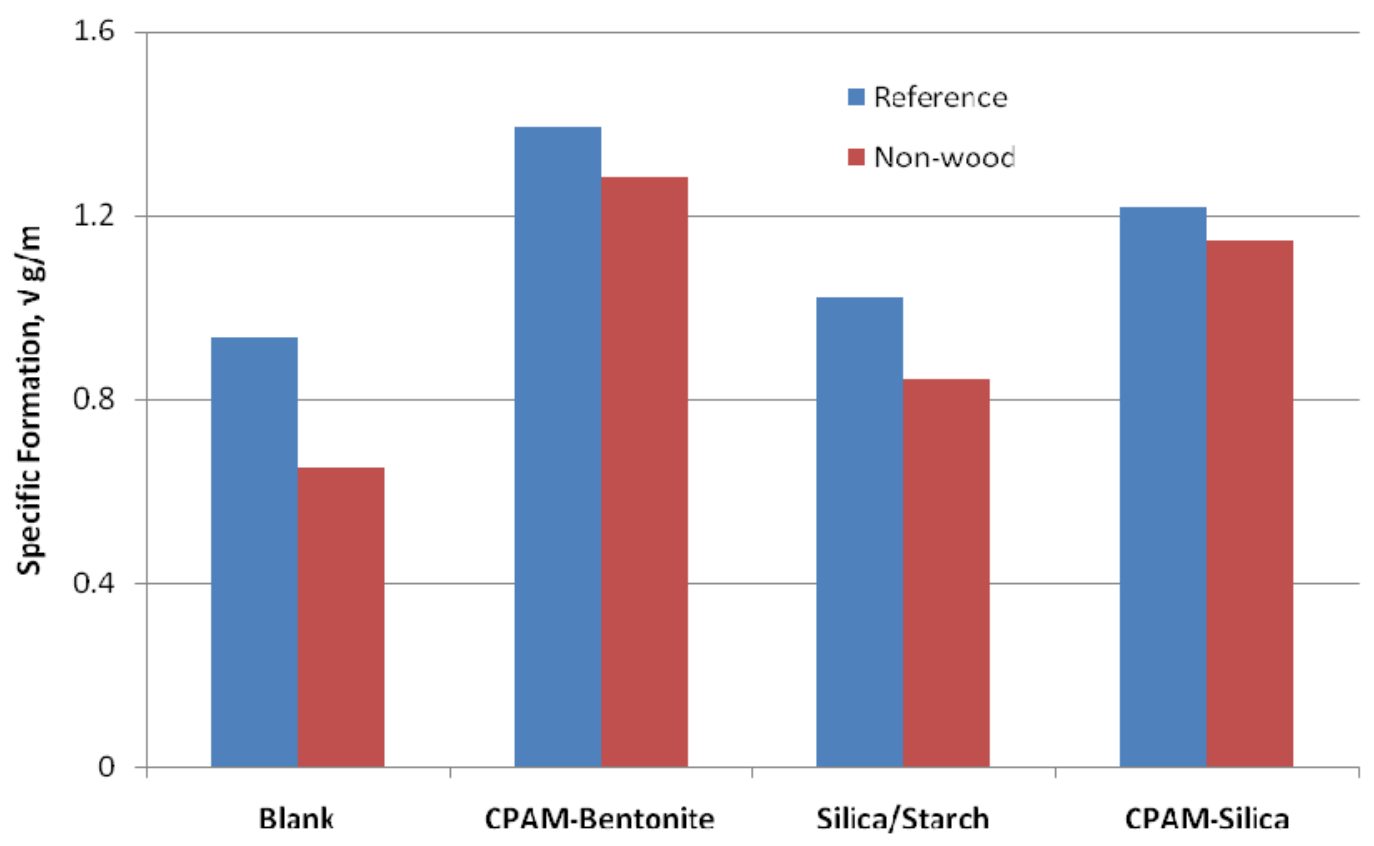

Fig. 10. Effect of different retention aids on formation when CPAM addition was $500 \mathrm{~g} / \mathrm{ton}$ and starch addition $12 \mathrm{~kg} / \mathrm{t}$

\section{Optimization of Retention Aid Dosage for Non-wood Containing Furnish}

The performance of the retention systems were compared at their optimal conditions. The appropriate chemical dosage selection included drainage, retention, and formation in addition to the economic aspect. The suggested dosages for the retention aids are shown in Table 4.

Table 4. Optimal Dosages of Retention Aids to be used with Non-Wood Furnish

\begin{tabular}{|l|c|c|}
\hline Retention aid & Polymer dosage, g/t & Microparticle dosage, $\mathbf{k g} / \mathbf{t}$ \\
\hline CPAM/bentonite & $300-500$ & 5 \\
\hline CPAM/silica & $250-500$ & 5 \\
\hline Silica/starch & 4000 & 4 \\
\hline
\end{tabular}

The optimal dosage for the silica/starch system is based on the dewatering enhancement effect. Starch dosage $4 \mathrm{~kg} / \mathrm{t}$ provided $4 \%$ drainage gain while filler and total retention were quite low. A graphical interpretation of the performance of the retention aids can be found in Fig. 11. The comparison in this figure is related to the optimal dosages mentioned in Table 4.

As can been seen from Fig. 11, all of the microparticle retention aid systems brought significant improvements to retention. The best dewatering was obtained with the bentonite-CPAM retention aid. However in the systems where formation is crucial, its application should be done with care because it had the biggest detrimental effect on the formation. 


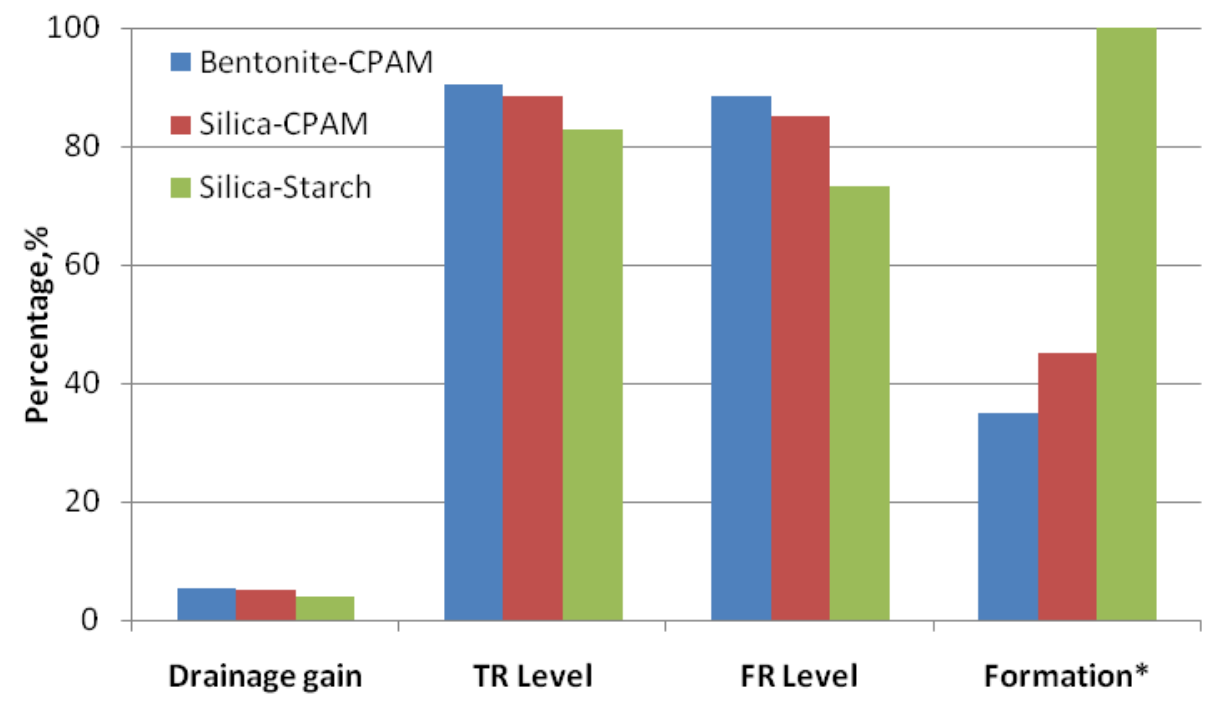

Fig. 11. Comparison of the retention aid perfomance for non-wood furnish at optimal dosages mentioned in Table 4. The figures show how much the retention aid has improved a certain value except: *Formation $=$ Formation without $/$ formation with retention aid (TR-Total Retention, FRFiller Retention).

The best formation was achieved with the silica-starch retention aid and this allows us to propose its usage in systems where formation significantly affects the final product performance. The silica-CPAM retention aid provided results comparable to the bentonite-CPAM retention aid, but its usage seems less attractive because of economic reasons. However, it should be mentioned that there was no optimization work done for the silica-CPAM retention aid. One type of silica microparticles has been used for the silica-starch and silica-CPAM systems. As the literature shows (Andersson and Lindgren 1996), there are a lot of factors (shape, charge density, degree of micro aggregation etc.) that need to be taken in consideration while selecting a certain type of microparticles for a certain furnish. In contrast with the present work, in the study of Lai et al. in 2010, silica-CPAM retention aids have shown good results in drainage and retention of nonwood pulp-based furnishes.

One reason for the good effectiveness of the bentonite-CPAM retention aid could be in the lower anionicity of the non-wood furnish. Hubbe et al. (2009) mentioned that bentonite-based applications may be less charge-dependent than applications utilizing silica.

\section{CONCLUSIONS}

1. Microparticle-based retention aids can be used for the improvement of drainage of non-wood pulp containing furnishes. A bentonite-CPAM retention aid was found to be the most efficient for drainage enhancement. The maximum drainage obtained with the bentonite-CPAM system was 5.5\%. Besides improved drainage it also provided excellent total and filler retention. Retention, drainage, and formation can be controlled by varying the dosages of CPAM. 
2. Dewatering with the silica-starch system significantly depends on the zeta potential of the furnish, and it was highest when the zeta potential was on near zero. In addition, a silica-starch retention aid system provided the best formation among the tested retention aids. However, because of low filler retention, utilization of silica-starch retention aid is under consideration.

3. The addition of non-wood pulp significantly improved the formation of sheets and filler retention; moreover it may also improve the evenness of the filler distribution on the sheet.

4. The information obtained concerning the use of microparticle retention aids in non-wood pulp containing furnishes provides positive indications for papermaking. The selection of a retention system can be considered as one step, in addition to the pulping process selection, to broaden the use of non-wood pulp for papermaking in modern mills. This could improve local issues with raw material shortages and have a beneficial effect on global material transportation.

\section{ACKNOWLEDGEMENTS}

This work has been done within the PEGRES project, financed by the Academy of Finland, which aims at the sustainable production of pulp, paper, chemicals, and energy from non-wood raw material.

\section{REFERENCES CITED}

Andersson, K., and Lindgren, E. (1996). “Important properties of colloidal silica in microparticle systems,” Nordic Pulp \& Paper Research Journal 1(11), 15-21.

Antunes, E., Garcia, F. A. P., Ferreira, P., Blanco, A., Negro, C., and Graca Rasteiro, M. (2008a). "Use of new branched cationic polyacrylamides to improve retention and drainage in papermaking,” Industrial \& Engineering Chemistry Research 47(23), 9370-9375.

Antunes, E., Garcia, F., Ferreira, P., and Rasteiro, M. (2008b). “Correlating retention and drainage with flocculation: Effect of polyelectrolyte branching," Proceedings of AICHE 2008'. (http://www.nt.ntnu.no/users/skoge/prost/proceedings/aiche2008/data/papers/P122115.pdf)

Cheng, Z. (1994). "Papermaking properties of nonwood fiber pulps,” IPPTA 6 (2), 45-48.

Cheng, Z., and Paulapuro, H. (1996a). "Influence of fines on free drainage of wheat straw pulp,” Proceedings of the 3rd International Non-Wood Fiber Pulping and

Papermaking Conference, 15-18 October, 1996, Beijing, People’s Republic of China, vol. 2. Beijing: International Academic Publishers, 431-440.

Cheng, Z., and Paulapuro, H. (1996b). "Vacuum dewatering of wheat straw pulp," Proceedings of the 3rd International Non-Wood Fiber Pulping and Papermaking Conference, 15-18 October, 1996, Beijing, People’s Republic of China, Vol. 2. Beijing: International Academic Publishers, 514-523. 
Cho, B., Garnier, G., van de Ven, T., and Perrier, M. (2006). “A bridging model for the effects of a dual component flocculation system on the strength of fibre contacts in flocs of pulp fibers: Implications for control of paper uniformity,” Colloids and Surfaces A: Physicochem. Eng. Aspects 287, 117-125.

Guo, S., Zhan, H., Zhang, C., Fu, S., Hejnesson-Hultén, A., Basta, J., and Greschik, T. (2009). "Pulp and fiber characterization of wheat straw and eucalyptus pulps - A comparison,” BioResources 4(3), 1006-1016.

Hu, F., Chen, Y., and Xie, L. (2000) "Evaluation of the properties of alum and PAC on bleached wheat straw pulp using charge analysis,” Proceedings of the Fourth International Nonwood Fibre Pulping and Papermaking Conference (4th INWFPPC) Sep 18-21, 2000 Jinan, China, Vol. 2.

Hubbe, M. (2003). "Selecting lab tests to predict effectiveness of retention and drainage aid programs,” Paper Technology 44(8), 20-34.

Hubbe, M., and Heitmann, J. (2007). "Review of factors affecting the release of water from cellulosic fibers during paper manufacture,” BioResources 2(3), 500-533.

Hubbe, M., Nanko, H., and McNeal, M. (2009). "Retention aid polymer interactions with cellulosic surfaces and suspensions: A review,” BioResources 4(2), 850-906.

Ilvessalo-Pfäffli, M.-S. (1995). Fibre Atlas. Identification of Papermaking Fibres, Springer-Verlag, Berlin 400p.ISBN-978-3-540-55392-2.

Kerekes, R., and Schell, C. (1995). "Effects of fiber length and coarseness on pulp flocculation,” Tappi Journal 78(2), 133-139.

Khosravani, A., Latibari, A. J., Mirshokraei, A. A., Rahmaninia, M., and Nazhad, M. M. (2010). "Studying the effect of cationic starch-anionic nanosilica system on retention and drainage,” BioResources 5(2), 939-950.

Lai R., Guanglei Z., Yang W., Beihai H., Greschik T., (2010) Applications of ECFbleached wheat straw pulp in fine paper" dealing with micro particle system in furnish containing wheat straw pulp. 4th ISETPP, Guangzhou, China, Nov 8-10, Vol.3,1499-1502

Liimatainen, H. (2009). "Interactions between fibres, fines and fillers in papermaking," Ph.D. dissertation, University of Oulu, 2009, 71p.

Liu, W., Long, Y., Niu, M., Wang, Q., and Xie, L. (2000). "Retention effect of amphoteric starch /polyaluminum silicate sulfate on wheat straw pulps," Proceedings of the Fourth International Nonwood Fibre Pulping and Papermaking Conference (4th INWFPPC) Sep 18-21, 2000 Jinan, China, Vol. 2.

Muravyev, A. (2010). “Utilization of non-wood pulp in different fibers products,” Master of Science thesis, Lappeenranta University of Technology, $81 \mathrm{pp}$.

Nie, X. (2007). “IFC non-wood pulp study in China completed,” Paperi ja Puu 89(4), 186-187, 189, 191-192, 195.

Otterstedt, J-E., and Greenwood P. (2006). "Some important, fairly new uses of colloidal silica/silica sol,” In: Colloidal Silica: Fundamentals and Applications, Bergna, H., and Roberts, W. (eds.), CRC Press. ISBN 978-0-8247-0967-9, 737-756

Rousu, P., and Hytönen, K. (2007). "The role of nonwood fines constituents on pulp and paper properties," Proceedings of 2007 TAPPI Engineering, Pulping \& Environmental Conference, October 21-24, 2007, Jacksonville, FL, USA, Paper 50-3. 
Rousu, P., Malinen, H., Hultholm, T., Jokinen, M., Kajanto, I., Paltakari, J., and Paltakari, H. (2010). "Wet pressing of wheat straw pulp - Correlations between dewatering parameters,” Nordic Pulp and Paper Research Journal 25(3), 277-287.

Rousu, P., Rousu, P., and Antilla J. (2002). "Sustainable pulp production from agricultural waste,” Resources, Conservation and Recycling 35, 85-103.

Solberg, D., and Wågberg, L. (2000). "On the mechanism of GCC filler retention during dewatering - New techniques and initial findings," Journal of Pulp and Paper Science 28 (6), 183-188.

Vainio, A., and Paulapuro, H. (2007). "Interfiber bonding and fiber segment activation in paper,” BioResources 2(3), 442-458.

Worrell, E., Prince, L., Neelis, M., Galitsky, C., Nan, Zhou. (2008) World Best Practice Energy Intensity Values for Selected Industrial Sectors. Report. U.S. Department of Energy. p. 33

Wågberg, L., Zhao, X., Fineman, I., and Feng, L. (1990). "Effects of retention aids on retention and dewatering of wheat-straw pulp,” TAPPI Journal 73(4), 177-182.

Xuan, Z., and Huiren, H. (2000). "Study on quaternary ammonium polyacrylamide used as retention and drainage aids for bleached wheat straw pulp,” Proceedings of the Fourth International Nonwood Fibre Pulping and Papermaking Conference (4th INWFPPC) Sep 18-21, 2000 Jinan, China, Vol. 2.

Yang, D.-Y., Nie, X.-Z., and Yuan, S.-Z. (1996). "Drainage aids for bleached wheat straw," Proceedings of the 3rd International Non-wood Fiber Pulping and papermaking Conference, Beijing, China, 441-450.

Ye, X.-C., Tanaka, H., and Sumimoto, M. (1990). "Effects of network-type polyacrylamides on the drainage and retention of wheat straw pulp," Mokuzai Gakkaishi 36(1), 64-68.

Zhu, Y., Xie L-S., Long Y-Q., Liang W-Z. (1997). "Retention of fines in reed papermaking,” Asia Pulp and Paper 34 (4), 25-27.

Article submitted: November 8, 2010; Peer review completed: December 11, 2011;

Revised version received and accepted: January 17, 2011; Published: January 20, 2011. 